Check for updates

Cite this: Phys. Chem. Chem. Phys., 2019, 21, 24950

Received 20th September 2019, Accepted 1st November 2019

DOI: $10.1039 / c 9 c p 05191 k$

rsc.li/pccp

\section{Assignment of the solid state spectra of the group VI hexacarbonyls by inelastic neutron scattering spectroscopy $\dagger$}

\author{
Stewart F. Parker (D)*a and Upali A. Jayasooriya ${ }^{b}$ \\ The solid state vibrational spectra of $M(C O)_{6},(M=C r, M o, W)$ in the region below $800 \mathrm{~cm}^{-1}$ have \\ been assigned by a combination of infrared, Raman and the first reported inelastic neutron scattering \\ (INS) spectra from homoleptic metal carbonyls. This region comprises of the lattice modes, the \\ $\mathrm{OC}-\mathrm{M}-\mathrm{CO}$ deformations, the $\mathrm{M}-\mathrm{C} \equiv \mathrm{O}$ bends and the $\mathrm{M}-\mathrm{C}$ stretches. Three modes that are \\ forbidden in both the infrared and Raman spectra of the parent $O_{\mathrm{h}}$ symmetry gas phase molecule \\ occur in this region. The absence of selection rules for INS spectroscopy means that all three modes \\ are clearly seen for the first time, all previous work has relied on overtone and combination modes. \\ Periodic density functional theory calculations of the complete orthorhombic structure support the \\ assignments.
}

\section{Introduction}

The group VI metal hexacarbonyls $\mathrm{M}(\mathrm{CO})_{6},(\mathrm{M}=\mathrm{Cr}, \mathrm{Mo}, \mathrm{W})$ have been extensively studied over the years. ${ }^{1}$ Their uses are as diverse as precursors for organometallic reagents in synthetic chemistry ${ }^{2}$ and as metal sources in chemical vapour deposition processes. ${ }^{3-5}$ The vibrational spectroscopy of the compounds in the gas phase has been comprehensively investigated $^{6-9}$ and empirical ${ }^{6,7,9}$ and $a b$ initio $^{10-12}$ force fields derived. In contrast, the solid state spectra have been much less investigated, the most complete study was by Adams and Taylor ${ }^{13}$ who recorded polarised infrared and Raman spectra from single crystals at $77 \mathrm{~K}$. The spectra in the carbonyl stretch region have also been interpreted using a novel approach. ${ }^{14}$

However, there are still uncertainties in some of the assignments and these relate to modes that are both infrared and Raman forbidden under the gas phase molecule's $O_{\mathrm{h}}$ symmetry. Knowledge of these modes is largely based on overtone and combination modes and also that they become weakly allowed in the solid state. In the present work we use a combination of inelastic neutron scattering (INS) spectroscopy ${ }^{15}$ and periodic density functional theory ${ }^{16,17}$ (periodic-DFT) to provide complete assignments of the solid state spectra.

\footnotetext{
${ }^{a}$ ISIS Facility, STFC Rutherford Appleton Laboratory, Chilton, Didcot, Oxon OX11 oQX, UK. E-mail: stewart.parker@stfc.ac.uk

${ }^{b}$ School of Chemical Sciences, University of East Anglia, Norwich NR4 7TJ, UK $\dagger$ Electronic supplementary information (ESI) available. See DOI: 10.1039/ c9cp05191k
}

\section{Experimental}

The INS spectra were recorded using TOSCA. ${ }^{18} 10-15 \mathrm{~g}$ of the compound $\left(\mathrm{Cr}(\mathrm{CO})_{6} 98 \%, \mathrm{Mo}(\mathrm{CO})_{6} 99.9 \%, \mathrm{~W}(\mathrm{CO})_{6} 97 \%\right.$, all from Aldrich and used as received) was loaded into a sealed can in an argon-filled dry box. The sample was then cooled to $\sim 20 \mathrm{~K}$ and the spectrum recorded for $\sim 12$ hours. Raman spectra were recorded at $7 \mathrm{~K}$ using an upgraded version of a Renishaw InVia spectrometer, that has been previously described. ${ }^{19}$ The upgrade consists of an additional laser operating at $532 \mathrm{~nm}$ and improved laser rejection filters with a low energy cut-off of $\sim 40 \mathrm{~cm}^{-1}$. Room temperature infrared spectra were recorded using a Bruker Vertex70 FTIR spectrometer, over the range 20 to $4000 \mathrm{~cm}^{-1}$ at $4 \mathrm{~cm}^{-1}$ resolution with a DLaTGS detector using 64 scans and the Bruker Diamond ATR. The use of the ultra-wide range beamsplitter enabled the entire spectral range to be recorded without the need to change beamsplitters. Spectra at $150 \mathrm{~K}$ were recorded using the same spectrometer with a SpecAc Golden Gate low temperature ATR accessory. The accessory limits the attainable, lowest energy to $350 \mathrm{~cm}^{-1}$. As the low temperature data is significantly sharper, this is shown where possible, unfortunately, only room temperature data is available for the region below $150 \mathrm{~cm}^{-1}$. The spectra have been corrected for the wavelength-dependent variation in path length using the Bruker software.

Dispersion corrected periodic DFT calculations of the crystalline structures were carried out using the plane-wave pseudopotential method implemented in the CASTEP code. ${ }^{16,17}$ Exchange and correlation were approximated using the Perdew-BurkeErnzerhof (PBE) functional, ${ }^{20}$ with the Tkatchenko-Scheffler (TS) dispersion correction scheme ${ }^{21}$ within the generalized gradient 


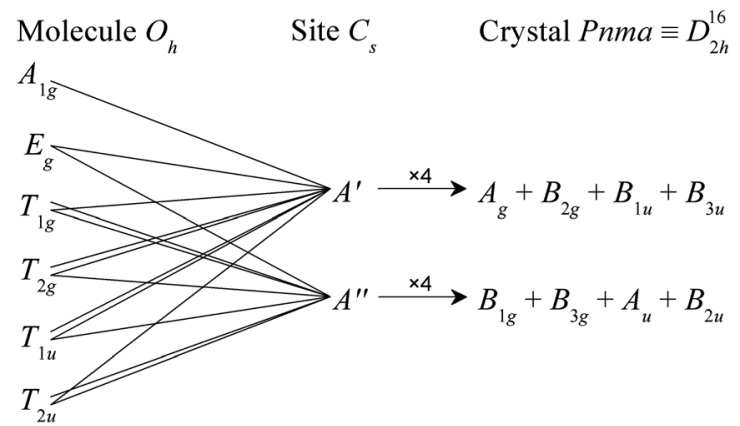

Fig. 1 Correlation diagram for the metal hexacarbonyls from the gas phase to the solid state. All gerade modes are Raman active, $B_{1 u}, B_{2 u}$, $B_{3 u}$, are infrared active and $A_{u}$ is inactive in both forms of spectroscopy. Note that all modes are allowed in INS spectroscopy.

approximation (GGA). Norm-conserving pseudopotentials were generated using the kinetic-energy optimised method ${ }^{22}$ with a plane-wave cut-off energy of 830 (Cr, Mo) or $900 \mathrm{eV}$ (W). Brillouin-zone sampling of electronic states was performed on a $6 \times 6 \times 8$ Monkhorst-Pack grid (36 k-points). The equilibrium structure, an essential prerequisite for lattice dynamics calculations was obtained by Broyden-Fletcher-Goldfarb-Shanno (BFGS) geometry optimization after which the residual forces were converged to zero within $\pm 0.0017 \mathrm{eV} \AA^{-1}$. Phonon frequencies were obtained by diagonalization of dynamical matrices computed using density-functional perturbation theory ${ }^{23}$ (DFPT). An analysis of the resulting eigenvectors was used to map the computed modes to the corresponding irreducible representations of the point group and assign IUPAC symmetry labels. DFPT was also used to compute the dielectric response and the Born effective charges, and from these the mode oscillator strength tensor and infrared absorptivity were calculated. In addition to the direct evaluation of frequencies and intensities at zero wavevector, phonon dispersion was also calculated along high symmetry directions throughout the Brillouin zone. For this purpose, dynamical matrices were computed on a regular grid of wavevectors throughout the Brillouin zone and Fourier interpolation was used to extend the computed grid to the desired fine set of points along the high-symmetry paths. ${ }^{24}$ The INS spectra were generated from the CASTEP output using ACLIMAX. ${ }^{25}$

\section{Results and discussion}

All three metal hexacarbonyls crystallise in space group Pnma $\left(D_{2 \mathrm{~h}}^{16}\right.$ number 62$)$ with four molecules in the unit cell, each

Table 1 Comparison of experimental and calculated bond distances and angles in $M(C O)_{6}(M=C r, M o, W)$. The calculated values are from the lattice and geometry optimised calculations with inclusion of the TS dispersion correction

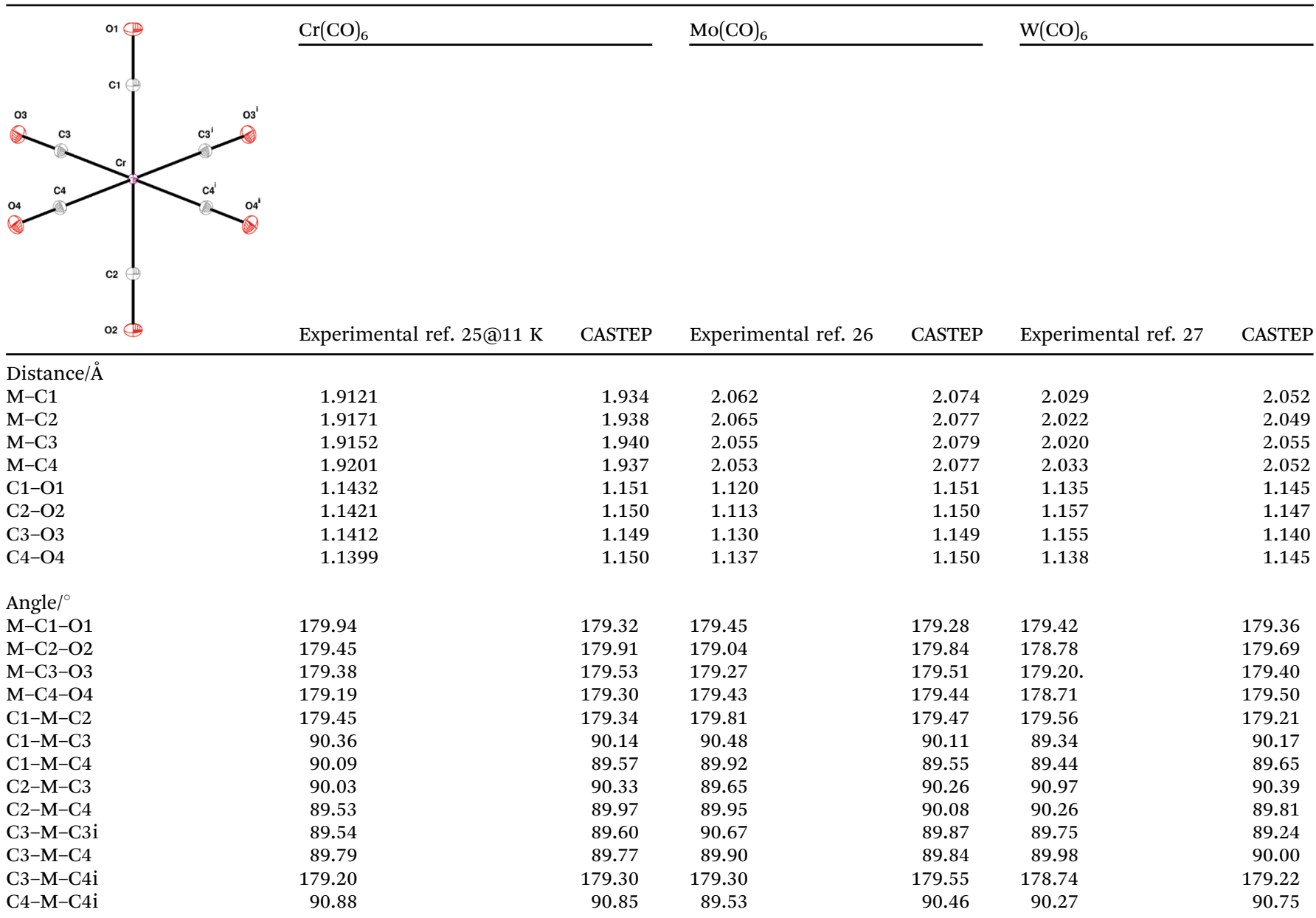


occupying a site of $C_{\mathrm{s}}$ symmetry, $\left(\mathrm{Cr}(\mathrm{CO})_{6},{ }^{26} \mathrm{Mo}(\mathrm{CO})_{6},{ }^{27}\right.$ $\mathrm{W}(\mathrm{CO})_{6}^{28}$.

In the gas phase, the $O_{\mathrm{h}}$ symmetry results in 13 modes: three $\mathrm{C} \equiv \mathrm{O}$ stretches $\left(\mathrm{A}_{1 \mathrm{~g}}, \mathrm{E}_{\mathrm{g}}, \mathrm{T}_{1 \mathrm{u}}\right)$, three $\mathrm{M}-\mathrm{CO}$ stretches $\left(\mathrm{A}_{1 \mathrm{~g}}, \mathrm{E}_{\mathrm{g}}\right.$, $\left.\mathrm{T}_{1 \mathrm{u}}\right)$, four $\mathrm{M}-\mathrm{C} \equiv \mathrm{O}$ bends $\left(\mathrm{T}_{1 \mathrm{~g}}, \mathrm{~T}_{1 \mathrm{u}}, \mathrm{T}_{2 \mathrm{~g}}, \mathrm{~T}_{2 \mathrm{u}}\right)$ and three OC-M-CO deformations $\left(\mathrm{T}_{1 \mathrm{u}}, \mathrm{T}_{2 \mathrm{~g}}, \mathrm{~T}_{2 \mathrm{u}}\right)$. The $\mathrm{C} \equiv \mathrm{O}$ stretch modes occur at $\sim 2000-2150 \mathrm{~cm}^{-1}$, the $\mathrm{M}-\mathrm{CO}$ stretches and $\mathrm{M}-\mathrm{C} \equiv \mathrm{O}$ bends at $\sim 300-700 \mathrm{~cm}^{-1}$, and the OC-M-CO deformations below $150 \mathrm{~cm}^{-1}$. The $\mathrm{A}_{1 \mathrm{~g}}$, $\mathrm{E}_{\mathrm{g}}$ and $\mathrm{T}_{2 \mathrm{~g}}$ modes are Raman active, the $T_{1 u}$ are infrared active and the $T_{1 g}$ and $T_{2 u}$ are inactive in both forms of spectroscopy. The effect of the $C_{\mathrm{s}}$ site symmetry is to formally remove all the degeneracies and the factor group splitting results in a quadrupling of the modes, as shown in Fig. 1. However, in all three cases, the geometry is that of a near-regular octahedron, Table 1 , and for most of the modes both the site group and factor group splitting is small. ${ }^{13}$

In the solid state, all the modes have components that are infrared or Raman allowed, in reality, the forbidden modes give, at best, very weak transitions and they have usually been obtained from overtone or combination bands. ${ }^{29}$ INS spectroscopy has no selection rules, thus all modes are allowed. The resolution of INS spectrometers in the $\mathrm{C} \equiv \mathrm{O}$ stretch region is insufficient to resolve the modes, however, in the region below $800 \mathrm{~cm}^{-1}$, the modes are more widely separated and the spectral resolution is much better. Fortunately, this is also the region where the forbidden modes occur and these are the focus of this paper.

The INS, Raman and infrared spectra of $\mathrm{Cr}(\mathrm{CO})_{6}, \mathrm{Mo}(\mathrm{CO})_{6}$ and $\mathrm{W}(\mathrm{CO})_{6}$ in the $0-800 \mathrm{~cm}^{-1}$ region are shown in Fig. $2-4$ respectively. In the $300-800 \mathrm{~cm}^{-1}$ region, seven modes are expected: three Raman active, two infrared active and two forbidden (in $O_{\mathrm{h}}$ symmetry) modes. Comparison of the spectra immediately identifies the forbidden modes at 365 and $511 \mathrm{~cm}^{-1}$ (Cr), 343 and $510 \mathrm{~cm}^{-1}$ (Mo) and 362 and $523 \mathrm{~cm}^{-1}$ (W).

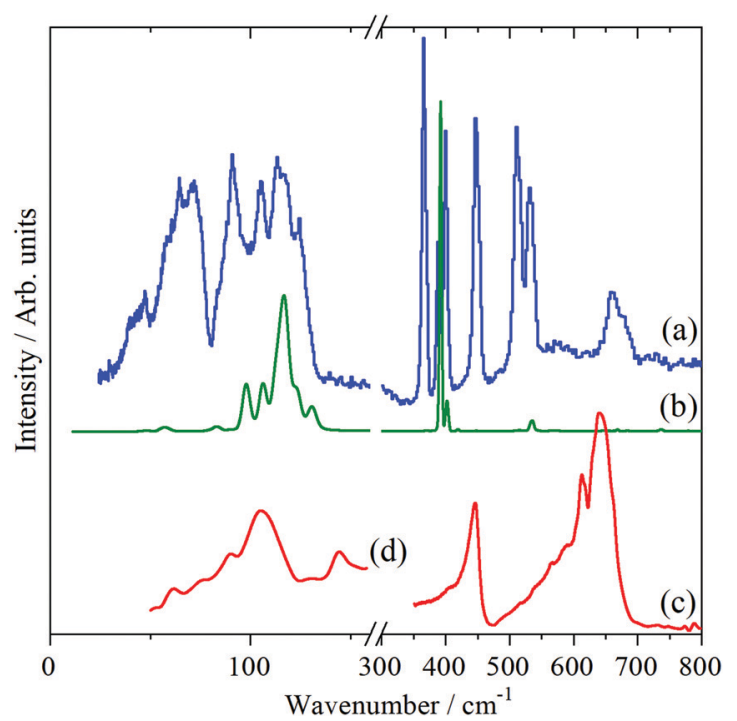

Fig. 2 Vibrational spectra of $\mathrm{Cr}(\mathrm{CO})_{6}$ in the $0-800 \mathrm{~cm}^{-1}$ region: (a) INS at $10 \mathrm{~K}$, (b) Raman at $7 \mathrm{~K}$ and infrared at (c) $150 \mathrm{~K}\left(400-800 \mathrm{~cm}^{-1}\right)$ and (d) room temperature, $\left(<200 \mathrm{~cm}^{-1}\right)$. (d) is $\times 5$ ordinate expanded relative to (c).

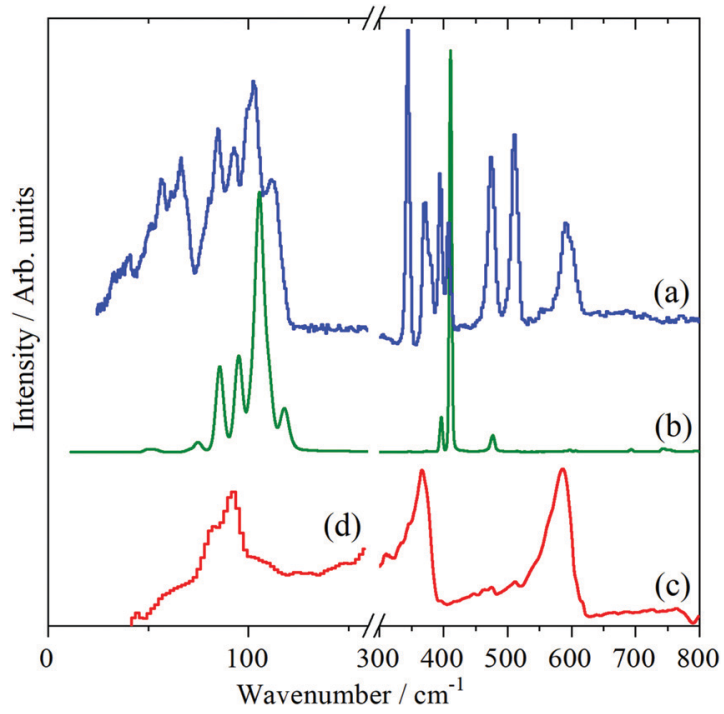

Fig. 3 Vibrational spectra of $\mathrm{Mo}(\mathrm{CO})_{6}$ in the $0-800 \mathrm{~cm}^{-1}$ region: (a) INS at $10 \mathrm{~K}$, (b) Raman at $7 \mathrm{~K}$ and infrared at (c) $150 \mathrm{~K}\left(400-800 \mathrm{~cm}^{-1}\right)$ and (d) room temperature, $\left(<200 \mathrm{~cm}^{-1}\right)$. (d) is $\times 5$ ordinate expanded relative to (c).

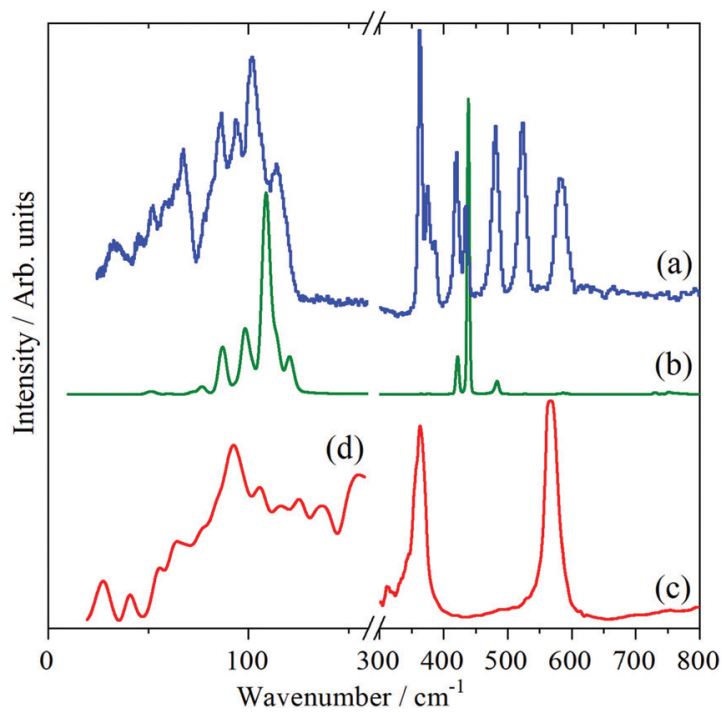

Fig. 4 Vibrational spectra of $W(C O)_{6}$ in the $0-800 \mathrm{~cm}^{-1}$ region: (a) INS at $10 \mathrm{~K}$, (b) Raman at $7 \mathrm{~K}$ and infrared at (c) $150 \mathrm{~K}\left(400-800 \mathrm{~cm}^{-1}\right)$ and (d) room temperature, $\left(<200 \mathrm{~cm}^{-1}\right)$. (d) is $\times 5$ ordinate expanded relative to (c).

In the very low energy region, $0-150 \mathrm{~cm}^{-1}$, the three OC-M-CO deformations occur, one of which is forbidden under $O_{\mathrm{h}}$ symmetry. However, the 12 translational (three acoustic and nine optic) and 12 librational modes also occur (three of each type for each of the four molecules in the primitive cell) in this region. This results in the INS spectra being very congested, since all of these will contribute to the INS spectrum. However, it can be seen that in all the INS spectra there are two main areas of intensity: $0-80$ and $80-150 \mathrm{~cm}^{-1}$.

In the case of $\operatorname{Cr}(\mathrm{CO})_{6}$, there are three clear peaks at 91,105 and $115 \mathrm{~cm}^{-1}$. The infrared and Raman spectra show that there are (relatively) strong modes at $90-100$ and $110-115 \mathrm{~cm}^{-1}$ 


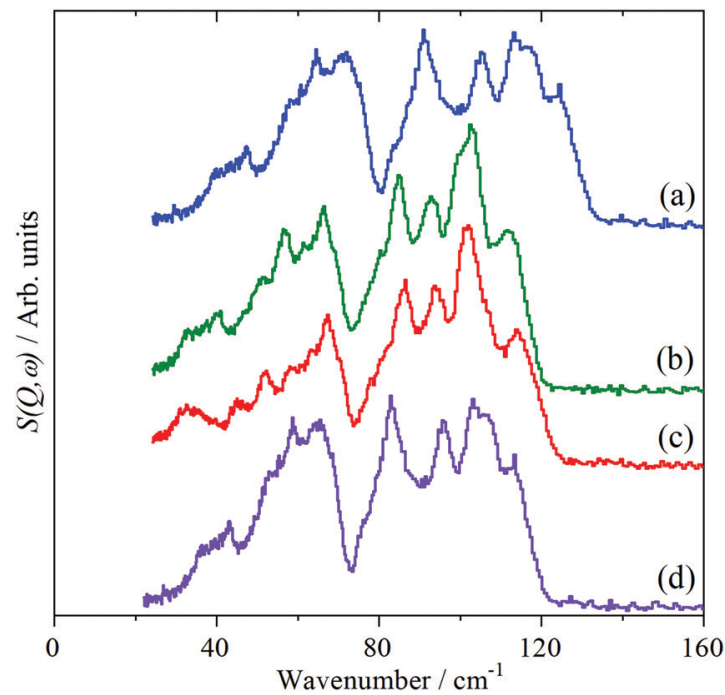

Fig. 5 INS spectra of: (a) $\mathrm{Cr}(\mathrm{CO})_{6}$ (b) $\mathrm{Mo}(\mathrm{CO})_{6}$, (c) $\mathrm{W}(\mathrm{CO})_{6}$ and (d) $\mathrm{Cr}(\mathrm{CO})_{6}$ scaled by 0.91 in the lattice mode and $\mathrm{OC}-\mathrm{M}-\mathrm{CO}$ bend region.

respectively, which are assigned to the allowed modes, ${ }^{9,13}$ accordingly the lowest energy peak at $91 \mathrm{~cm}^{-1}$ is assigned to the forbidden mode. The only previous ${ }^{9}$ assignment of this mode was at $68 \mathrm{~cm}^{-1}$ and was based on a very weak combination mode in the infrared spectrum of the gas phase molecule. The $+23 \mathrm{~cm}^{-1}$ shift on going from the gas phase to the solid state is consistent with the other two OC-M-CO deformation modes which shift by $+8 \mathrm{~cm}^{-1}$ and $+24 \mathrm{~cm}^{-1}$. These three modes probably account for most of the intensity in the $80-150 \mathrm{~cm}^{-1}$ range in the INS spectra, suggesting that the lattice modes result in the $0-80 \mathrm{~cm}^{-1}$ massif.

For $\mathrm{Mo}(\mathrm{CO})_{6}$ and $\mathrm{W}(\mathrm{CO})_{6}$, the $0-150 \mathrm{~cm}^{-1}$ regions are almost superimposable and strongly resemble a "squashed" version of that of $\mathrm{Cr}(\mathrm{CO})_{6}$, as shown in Fig. 5. Accordingly, the OC-M-CO deformation modes are as for $\mathrm{Cr}(\mathrm{CO})_{6}$, with the forbidden mode observed at 85 and $86 \mathrm{~cm}^{-1}$ for $\mathrm{Mo}(\mathrm{CO})_{6}$ and $\mathrm{W}(\mathrm{CO})_{6}$ respectively. Table 2 lists the assignments.

In order to confirm these assignments, periodic density functional theory (DFT) calculations of the complete unit cell

Table 2 Assignments for the $0-800 \mathrm{~cm}^{-1}$ region of $\mathrm{M}(\mathrm{CO})_{6}(\mathrm{M}=\mathrm{Cr}, \mathrm{MO}$, $W$ ) in the gas phase ${ }^{a}$ and the solid state with $O_{\mathrm{h}}$ symmetry

\begin{tabular}{|c|c|c|c|c|c|c|c|}
\hline \multirow[b]{2}{*}{ Mode } & \multicolumn{2}{|c|}{$\mathrm{Cr} / \mathrm{cm}^{-1}$} & \multicolumn{2}{|c|}{$\mathrm{Mo} / \mathrm{cm}^{-1}$} & \multicolumn{2}{|c|}{$\mathrm{W} / \mathrm{cm}^{-1}$} & \multirow[b]{2}{*}{ Description $^{b}$} \\
\hline & $\begin{array}{l}\text { Solid } \\
\text { (INS) }\end{array}$ & Gas & $\begin{array}{l}\text { Solid } \\
\text { (INS) }\end{array}$ & Gas & $\begin{array}{l}\text { Solid } \\
\text { (INS) }\end{array}$ & Gas & \\
\hline $\mathrm{T}_{2 \mathrm{u}}$ & 91 & 67.9 & 85 & 60 & 86 & 61.4 & $\delta(\mathrm{C}-\mathrm{M}-\mathrm{C})$ \\
\hline $\mathrm{T}_{1 \mathrm{u}}$ & 105 & 97.2 & 93 & 81.6 & 94 & 82.0 & $\delta(\mathrm{C}-\mathrm{M}-\mathrm{C})$ \\
\hline$T_{2 g}$ & 117 & 89.7 & 103 & 79.2 & 102 & 81.4 & $\delta(\mathrm{C}-\mathrm{M}-\mathrm{C})$ \\
\hline$T_{1 g}$ & 367 & 364.1 & 344 & 341.6 & 362 & 361.6 & $\delta(\mathrm{M}-\mathrm{C} \equiv \mathrm{O})$ \\
\hline$A_{1 g}$ & 391 & 379.2 & 410 & 391.2 & 434 & 426 & $\nu(\mathbf{M}-\mathrm{C})$ \\
\hline $\mathrm{E}_{g}$ & 400 & 390.6 & 393 & 381 & 419 & 410 & $\nu(\mathbf{M}-\mathrm{C})$ \\
\hline $\mathrm{T}_{1 \mathrm{u}}$ & 446 & 440.5 & 370 & 367.2 & 376 & 374.4 & $\delta(\mathrm{M}-\mathrm{C} \equiv \mathrm{O})$ \\
\hline $\mathrm{T}_{2 \mathrm{u}}$ & 511 & 510.9 & 512 & 507.2 & 523 & 521.3 & $\delta(\mathrm{M}-\mathrm{C} \equiv \mathrm{O})$ \\
\hline $\mathrm{T}_{2 \mathrm{~g}}$ & 533 & 532.1 & 475 & 477.4 & 481 & 482.0 & $\delta(\mathrm{M}-\mathrm{C} \equiv \mathrm{O})$ \\
\hline $\mathrm{T}_{1 \mathrm{u}}$ & 660 & 668.1 & 590 & 595.6 & 583 & 586.6 & $\nu(\mathbf{M}-\mathbf{C})$ \\
\hline
\end{tabular}

${ }^{a}$ Ref. $9 .{ }^{b} \delta=$ bend, $\nu=$ stretch. are required. Comparison of observed and calculated INS spectra is an exacting test $t^{15}$ of the accuracy of such studies.

The results of a series of calculations for $\mathrm{Cr}(\mathrm{CO})_{6}$ are shown in Fig. 6 and summarised in Table 3. All of these are generated from calculations across the complete Brillouin zone, so as to include the effects of vibrational dispersion (variation of transition energy with wavevector). As may be seen from Fig. 7, this is significant in the region below $200 \mathrm{~cm}^{-1}$, but less so for the stretch and deformation region. (The dispersion curves for the $\mathrm{C} \equiv \mathrm{O}$ stretch region and the corresponding sets for $\mathrm{Mo}(\mathrm{CO})_{6}$ and $\mathrm{W}(\mathrm{CO})_{6}$ are shown in Fig. S1-S7 of the ESI $\left.\dagger\right)$. From Fig. 6, it can be seen that the agreement between observed and calculated spectra, is very sensitive to the details of the method used for the lattice mode region, but less so for the stretch and deformation region. The calculations with the experimental
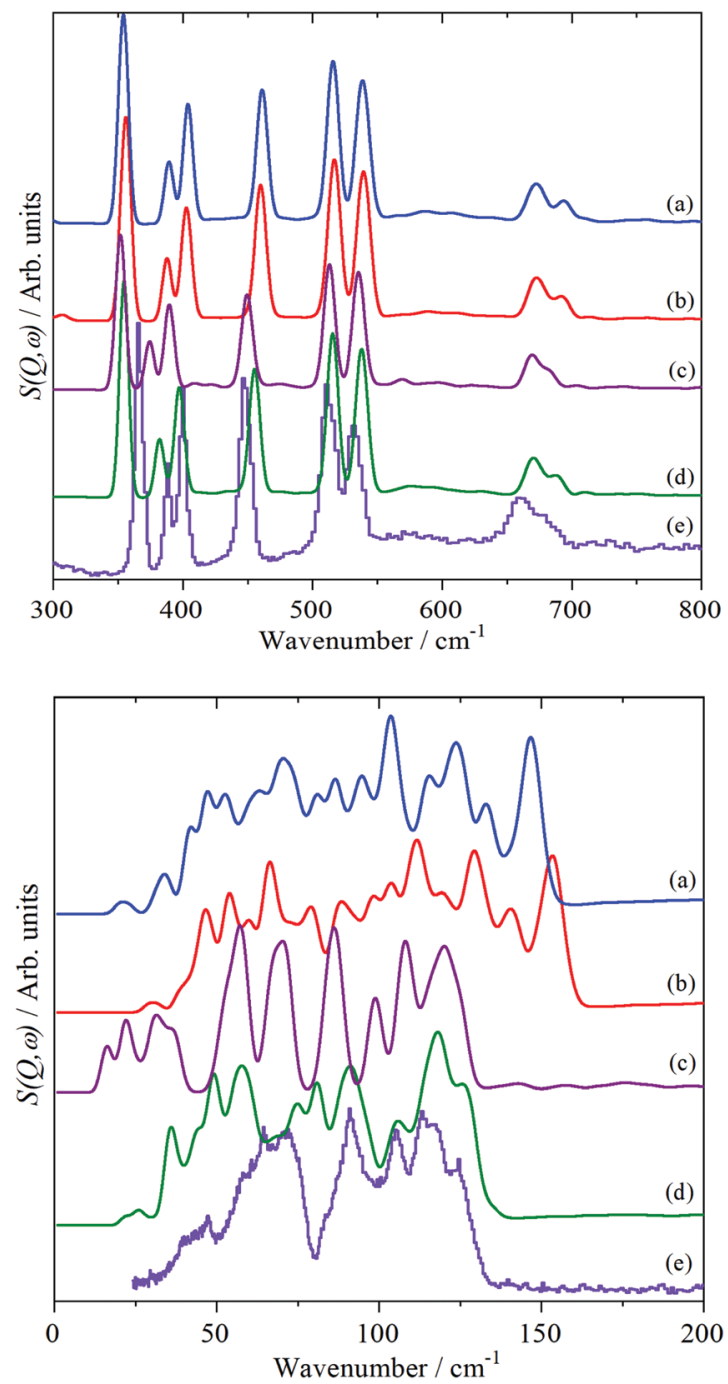

Fig. 6 Comparison of observed and calculated INS spectra of $\mathrm{Cr}(\mathrm{CO})_{6}$ in the $\mathrm{Cr}-\mathrm{C}$ stretch and $\mathrm{Cr}-\mathrm{C} \equiv \mathrm{O}$ bend region (upper panel) and the lattice mode and $\mathrm{OC}-\mathrm{Cr}-\mathrm{CO}$ bend region (lower panel). (a) Calculated at the experimental lattice parameters, (b) calculated at the experimental lattice parameters with the TS correction, (c) calculated with optimised lattice parameters, (d) calculated with optimised lattice parameters and with the TS correction and (e) experimental data. 
Table 3 Comparison of relative total energies and lattice parameters in $\mathrm{M}(\mathrm{CO})_{6}$

\begin{tabular}{|c|c|c|c|c|c|c|c|}
\hline \multirow[b]{2}{*}{ Method } & \multirow[b]{2}{*}{ Metal } & \multirow{2}{*}{$\begin{array}{l}\text { Relative }^{a} \text { total } \\
\text { energy/eV }\end{array}$} & \multicolumn{3}{|c|}{ Lattice parameters/Å } & \multicolumn{2}{|c|}{ Cell volume } \\
\hline & & & $a$ & $b$ & $c$ & $\AA^{3}$ & $\Delta^{b_{0}} \%$ \\
\hline \multirow[t]{2}{*}{ Fixed at experimental lattice parameters (no TS correction) } & $\mathrm{Cr}$ & 4.3259 & 11.474 & 10.894 & 6.188 & 773.549 & 0 \\
\hline & W & 6.579 & 11.944 & 11.370 & 6.459 & 877.153 & 0 \\
\hline Lattice optimised $^{c}$ (no TS correction) & $\mathrm{Cr}$ & 3.4015 & 12.770 & 11.833 & 6.868 & 1037.894 & +34.2 \\
\hline & W & 0 & 11.944 & 11.370 & 6.459 & 877.153 & 0 \\
\hline \multirow[t]{3}{*}{ Lattice optimised with the TS correction included } & $\mathrm{Cr}$ & 0 & 11.741 & 11.117 & 6.308 & 823.284 & +6.4 \\
\hline & Mo & 0 & 11.970 & 11.374 & 6.438 & 876.610 & -1.5 \\
\hline & W & 0 & 11.875 & 11.360 & 6.417 & 865.540 & -1.3 \\
\hline
\end{tabular}

${ }^{a}$ Relative to lowest energy structure. ${ }^{b} \%$ difference in cell volume. ${ }^{c}$ Cell angles fixed at $90^{\circ}$ in order to maintain the Pnma symmetry, but cell lengths are allowed to optimise.

lattice parameters result in poor agreement, allowing the lattice lengths to optimise (but not the angles, so as to maintain the orthorhombic symmetry), results in much better agreement.

As these compounds have essentially zero permanent dipole moment, it follows that the solids are largely stabilised by van der Waals interactions. These are not included in conventional
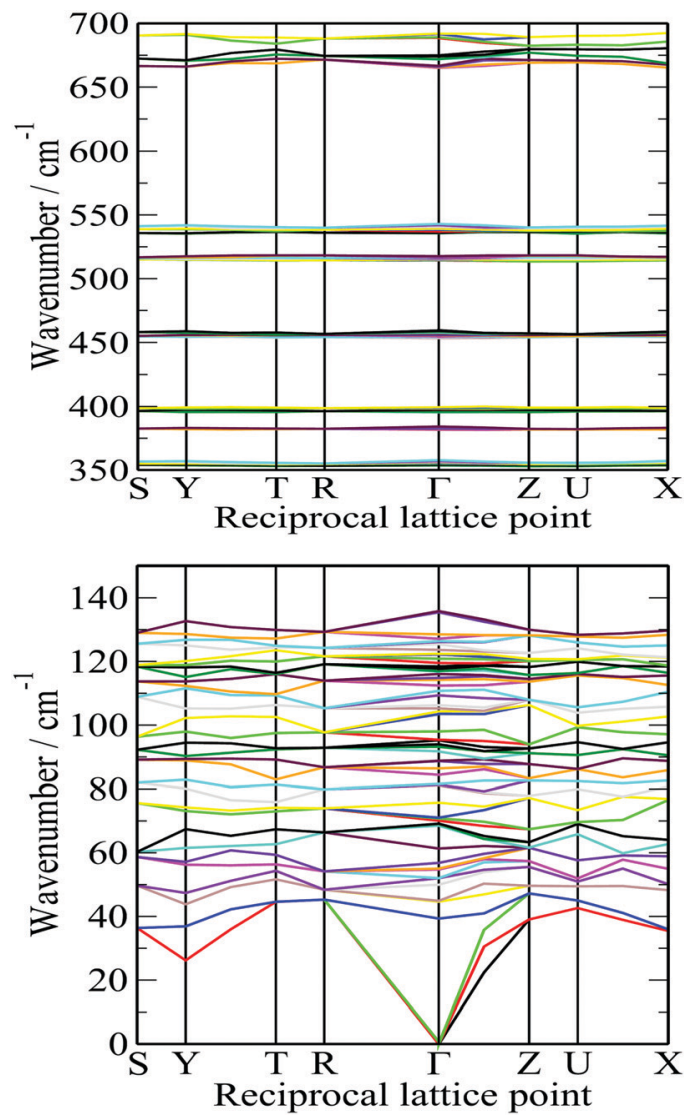

Fig. 7 Calculated dispersion curves of $\mathrm{Cr}(\mathrm{CO})_{6}$ in the $\mathrm{Cr}-\mathrm{C}$ stretch and $\mathrm{Cr}-\mathrm{C} \equiv \mathrm{O}$ bend region (upper panel) and the lattice mode and $\mathrm{OC}-\mathrm{Cr}-\mathrm{CO}$ bend region (lower panel). The calculations are for the lattice optimised structure with the TS correction and correspond to Fig. $5 \mathrm{~d}$.
DFT functionals, so to compensate for this an empirical correction is added to the functional. There are a variety of such methods, the most comprehensive currently available is that of Tkatchenko and Scheffler ${ }^{21}$ (TS). Inclusion of the TS dispersion correction does not greatly change the fixed lattice results, but it does significantly modify the optimised lattice calculations in several respects: the change in cell volume is reduced from $+34 \%$ to $+6.4 \%$, the acoustic modes (the bands below $50 \mathrm{~cm}^{-1}$ in Fig. 6c) harden and the profile of the $80-150 \mathrm{~cm}^{-1}$ feature is in excellent agreement with that found experimentally, Fig. 6e. Table 1 compares selected observed and calculated bond distances and angles for the lattice and geometry optimised structures with inclusion of the TS dispersion correction.

A calculation of an $O_{\mathrm{h}}$ symmetry $\mathrm{Cr}(\mathrm{CO})_{6}$ molecule in $10 \times 10 \times 10 \AA$ A cell, (which simulates a gas phase molecule) found that only the lowest three modes underwent a downshift of $>5 \mathrm{~cm}^{-1}$ (solid-gas phase), consistent with our assignment.

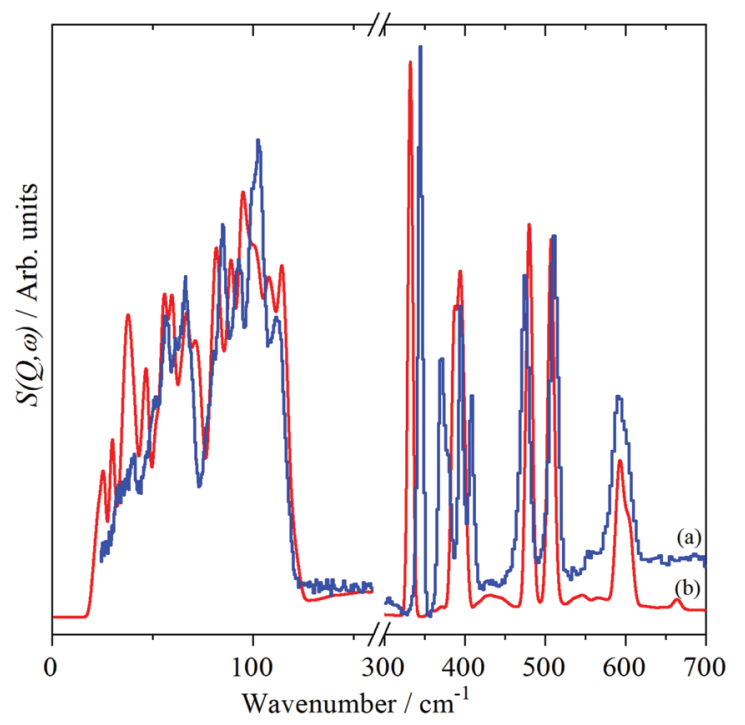

Fig. 8 Comparison of (a) observed and (b) calculated INS spectra of $\mathrm{Mo}(\mathrm{CO})_{6}$. 


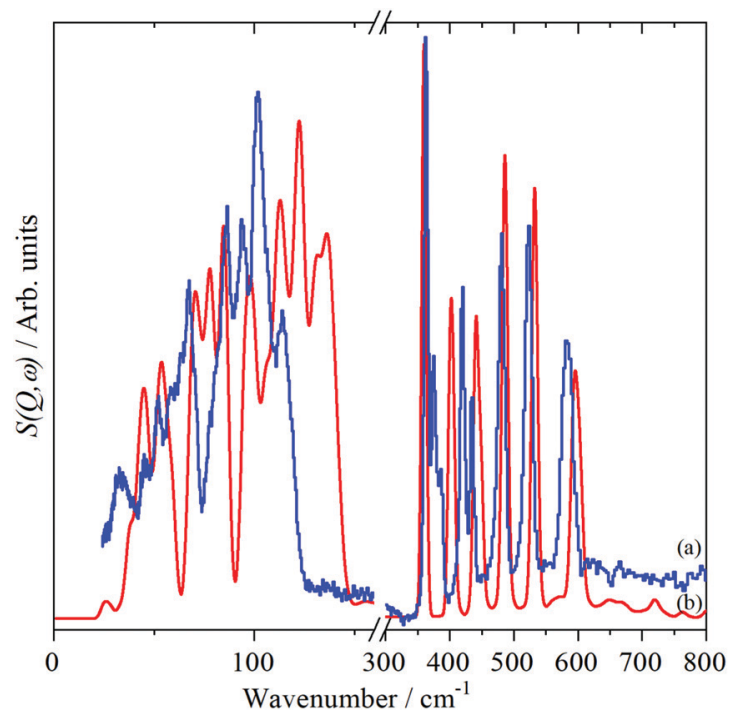

Fig. 9 Comparison of (a) observed and (b) calculated INS spectra of $\mathrm{W}(\mathrm{CO})_{6}$.

Fig. 8 and 9 show the comparison of the observed and calculated INS spectra for $\mathrm{Mo}(\mathrm{CO})_{6}$ and $\mathrm{W}(\mathrm{CO})_{6}$ respectively. Both calculated spectra are from lattice and geometry optimisations with the TS correction. It can be seen that the result for $\mathrm{Mo}(\mathrm{CO})_{6}$ is in good agreement with the observed spectrum, while that for $\mathrm{W}(\mathrm{CO})_{6}$ is in poor agreement for the region $<150 \mathrm{~cm}^{-1}$. We have no explanation for this event. It is noticeable that the lattice optimisation resulted in a small shrinkage of the lattice, Table 2, rather than an expansion as seen for $\mathrm{Cr}(\mathrm{CO})_{6}$. The contraction would harden the modes, but it does not explain why there is a difference between the Mo and $\mathrm{W}$ case.

The calculations confirm the assignments derived above. Tables S1-S3 (ESI $\dagger$ ) list the calculated modes with their assignments for all three molecules.

\section{Conclusions}

The solid state vibrational spectra of $\mathrm{M}(\mathrm{CO})_{6},(\mathrm{M}=\mathrm{Cr}, \mathrm{Mo}, \mathrm{W})$ in the region below $800 \mathrm{~cm}^{-1}$ have been assigned by a combination of infrared, Raman and the first reported inelastic neutron scattering (INS) spectra from homoleptic metal carbonyls. This has enabled the three modes that are forbidden in both the infrared and Raman spectra of the parent $O_{\mathrm{h}}$ symmetry gas phase molecule to be directly observed for the first time. Periodic density functional theory calculations of the complete orthorhombic structure support the assignments, although the agreement is not exact in the region below $100 \mathrm{~cm}^{-1}$, which highlights the difficulty of obtaining reliable assignments for the external modes (translations and librations) even for fairly simple molecules.

\section{Conflicts of interest}

There are no conflicts of interest to declare.

\section{Acknowledgements}

The STFC Rutherford Appleton Laboratory is thanked for funding and access to neutron beam facilities. Computing resources (time on the SCARF compute cluster for the CASTEP calculations) were provided by STFC's e-Science facility.

\section{References}

1 H. Werner, Angew. Chem., Int. Ed. Engl., 1990, 29, 1077.

2 L. S. Hegedus, Pure Appl. Chem., 1990, 62, 691.

3 C.-L. Chen and W.-C. J. Wei, J. Eur. Ceram. Soc., 2002, 22, 2883.

4 J. S. Cross and G. L. Schrader, Thin Solid Films, 1995, 259, 5. 5 K. K. Lai and H. H. Lamb, Thin Solid Films, 2000, 370, 114.

6 L. H. Jones, J. Chem. Phys., 1962, 36, 2375.

7 L. H. Jones, Spectrochim. Acta, 1963, 19, 329.

8 J. M. Smith and L. H. Jones, J. Mol. Spectrosc., 1966, 20, 248.

9 L. H. Jones, R. S. McDowell and M. Goldblatt, Inorg. Chem., 1969, 8, 2349.

10 V. Jonas and W. Thiel, J. Chem. Phys., 1995, 102, 8474.

11 V. Jonas and W. Thiel, Organometallics, 1998, 17, 353.

12 V. Jonas and W. Thiel, J. Phys. Chem., 1999, 103, 1381.

13 D. M. Adams and I. D. Taylor, J. Chem. Soc., Faraday Trans., 1982, 78, 1051.

14 U. A. Jayasooriya, J. Chem. Soc., Faraday Trans., 1994, 90, 1265. 15 P. C. H. Mitchell, S. F. Parker, A. J. Ramirez-Cuesta and J. Tomkinson, Vibrational Spectroscopy with Neutrons, World Scientific, Singapore, 2005.

16 S. J. Clark, M. D. Segall, C. J. Pickard, P. J. Hasnip, M. J. Probert, K. Refson and M. C. Payne, Z. Kristallogr., 2005, 220, 567.

17 K. Refson, S. J. Clark and P. R. Tulip, Phys. Rev. B: Condens. Matter Mater. Phys., 2006, 73, 155114.

18 S. F. Parker, F. Fernandez-Alonso, A. J. Ramirez-Cuesta, J. Tomkinson, S. Rudic, R. S. Pinna, G. Gorini and J. Fernández Castañon, J. Phys.: Conf. Ser., 2014, 554, 012003.

19 M. A. Adams, S. F. Parker, F. Fernandez-Alonso, D. J. Cutler, C. Hodges and A. King, Appl. Spectrosc., 2009, 63, 727-732.

20 J. Perdew, K. Burke and M. Ernzerhof, Phys. Rev. Lett., 1996, 77, 3865.

21 A. Tkatchenko and M. Scheffler, Phys. Rev. Lett., 2009, 102, 073005.

22 A. M. Rappe, K. M. Rabe, E. Kaxiras and J. D. Joannopoulos, Phys. Rev. B: Condens. Matter Mater. Phys., 1990, 41, 1227.

23 V. Milman, A. Perlov, K. Refson, S. J. Clark, J. Gavartin and B. Winkler, J. Phys.: Condens. Matter, 2009, 21, 485404.

24 X. Gonze, J.-C. Charlier and M. P. Teter, Phys. Rev. B: Condens. Matter Mater. Phys., 1994, 50, 13035-13038.

25 A. J. Ramirez-Cuesta, Comput. Phys. Commun., 2004, 157, 226.

26 B. N. Figgis and A. N. Sokolev, Acta Crystallogr., Sect. E: Struct. Rep. Online, 2004, 60, i9.

27 T. C. W. Mak, Z. Kristallogr., 1984, 166, 277.

28 F. Heinemann, H. Schmidt, K. Peters and D. Thiery, Z. Kristallogr., 1992, 198, 123.

29 T. Shimanouchi, J. Phys. Chem. Ref. Data, 1977, 6, 993. 